\title{
In this issue
}

Ole G. Mouritsen, Prannie Rhatigan

and José Lucas Pérez-Lloréns

The rise of seaweed gastronomy:

phycogastronomy

https://doi.org/10.1515/bot-2018-0041

Botanica Marina 2019; 62(3): 195-209
Review: Regional seaweed cuisines around the world have recently been rediscovered and reinvigorated, and many chefs up to the top level have initiated, often in collaboration with scientists, a trend towards a new seaweed gastronomy (phycogastronomy).

Keywords: food culture; gastronomy; human food; phycogastronomy; seaweeds; world cuisine.

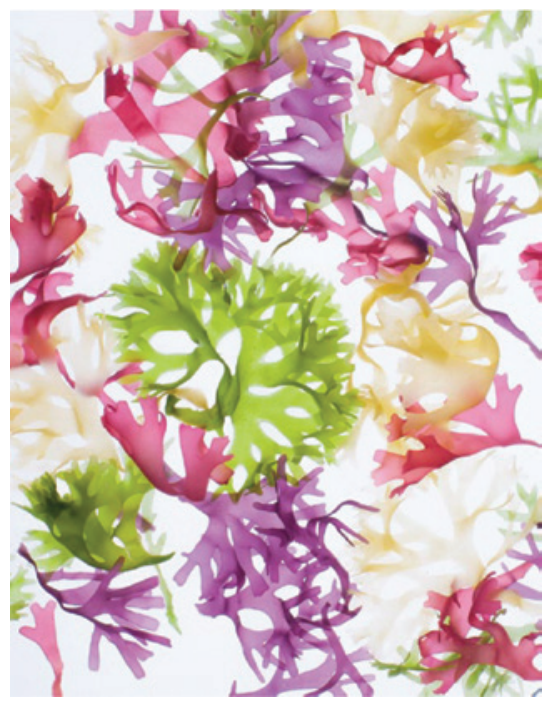

Review: Neglected tropical diseases (NTDs) affect 1.4 billion people in the poorest parts of the world. Here is an overview of the current status of algal natural products against NTDs.

Keywords: insect-borne
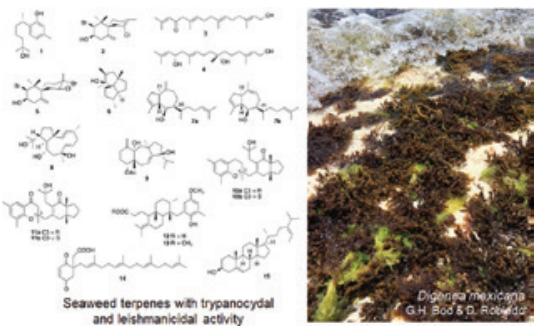

infections; leishmaniasis;

neglected tropical diseases;

seaweed; trypanosomiasis.
Michael S. Stekoll

The seaweed resources of Alaska

https://doi.org/10.1515/bot-2018-0064

Botanica Marina 2019; 62(3): 227-235
Review: Alaska, with its extensive coastline, has over 500 species of seaweeds that are resources for commercial and subsistence utilization, including harvests of herring spawn-on-kelp, and future mariculture of many species for food, feed, biofuels, climate mitigation and ecosystem services.

Keywords: aquaculture; biodiversity; kelps; mariculture; spawn-on-kelp.

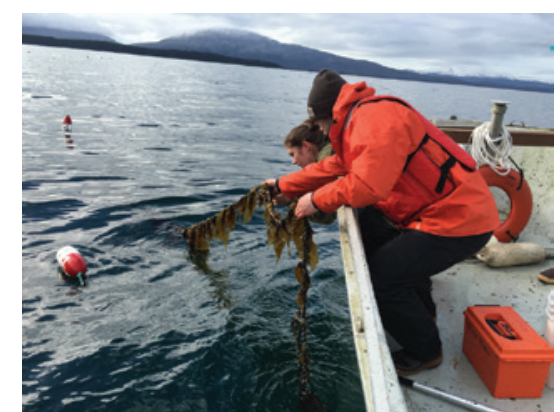


Carolina Camus, María del Carmen

Hernández-González and

Alejandro H. Buschmann

The seaweed resources of Chile over the period 2006-2016: moving from gatherers to cultivators

https://doi.org/10.1515/bot-2018-0030

Botanica Marina 2019; 62(3): 237-247
Review: Chile relies on the exploitation of natural seaweed stands, which are exported abroad mainly as dry biomass. This tendency is changing towards a more sustainable exploitation and cultivation, localized seaweed industry, with new investments in local valorization of the resources.

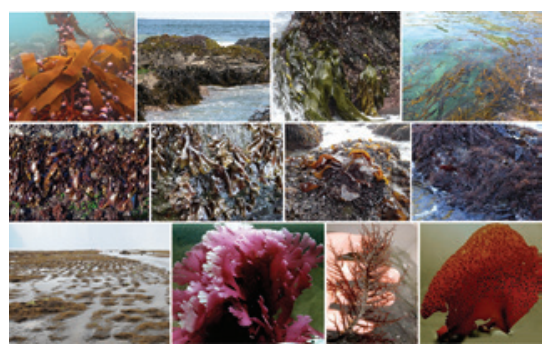

Keywords: Chile; hydrocolloids; Phaeophyceae; Rhodophyta; seaweed landings; volumes.
Antonella Petrocelli and Ester Cecere A 20-year update on the state of seaweed resources in Italy

https://doi.org/10.1515/bot-2018-0072

Botanica Marina 2019; 62(3): 249-264
Review: The update of our knowledge of "seaweed resources" in Italy showed that seaweed species are well studied. However, local populations are rarely exploited, mostly because their production at an industrial level has never taken off.

Keywords: Italy; Mediterranean Sea; resources; seaweed.

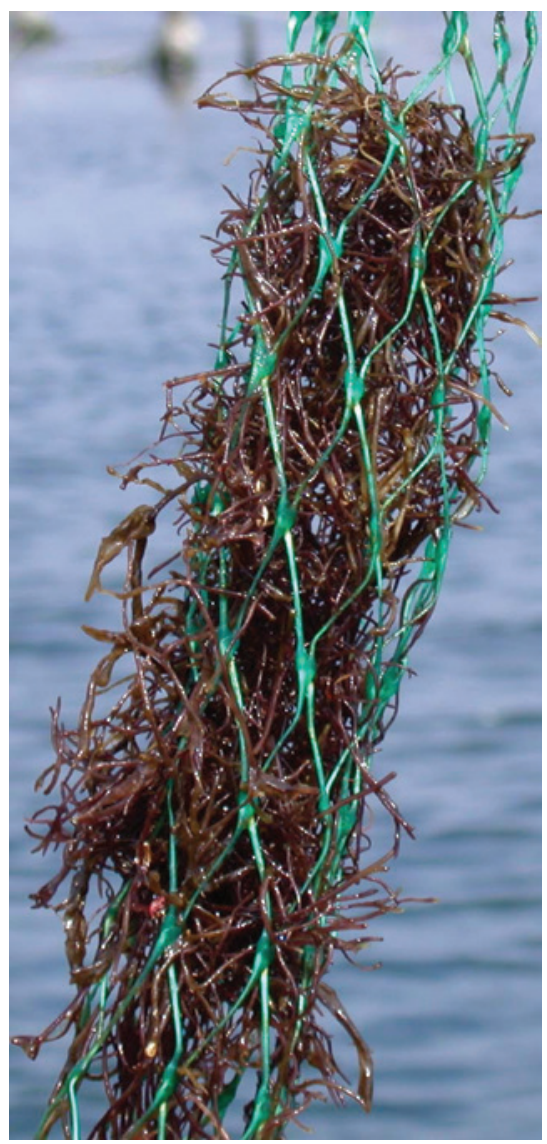


Siew-Moi Phang, Hui-Yin Yeong

and Phaik-Eem Lim

The seaweed resources of Malaysia

https://doi.org/10.1515/bot-2018-0067

Botanica Marina 2019; 62(3): 265-273
Review: Malaysia's tropical waters support a high diversity of seaweeds comprising 459 taxa in 72 families.

Keywords: checklist; cultivation; industry; seaweed resources.

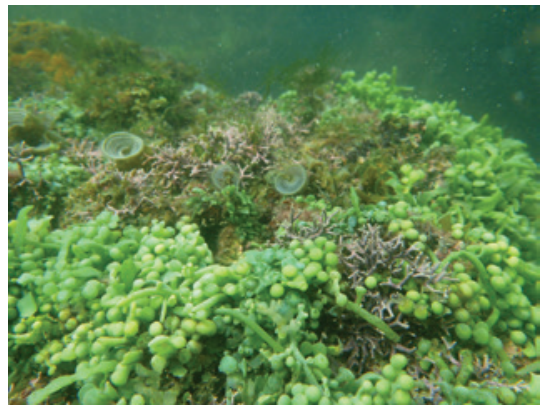

Erika Vázquez-Delfín, Yolanda FreilePelegrín, Hugo Pliego-Cortés and Daniel Robledo

Seaweed resources of Mexico: current knowledge and future perspectives

https://doi.org/10.1515/bot-2018-0070

Botanica Marina 2019; 62(3): 275-289
Review: Exploitation of seaweed resources in Mexico is currently based on a few species, however an increase in algal products demand and current research efforts suggests a high potential to produce biomass through aquaculture and diversify the species utilized.

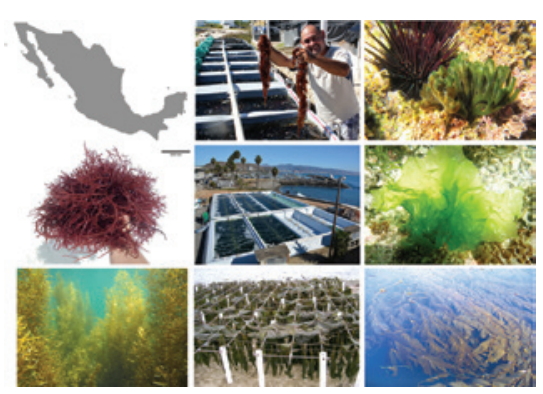

Keywords: biodiversity; economic seaweed; Mexico; Phaeophyceae; Rhodophyta. 